\title{
La autoridad de los profesores desde la perspectiva estudiantil
}

\author{
MARÍA PAULA PIERELLA \\ Universidad Nacional de Rosario, \\ Santa Fe, Argentina
}

\section{RESUMEN}

Este artículo aborda los resultados obtenidos a partir de una investigación centrada en explorar las visiones de estudiantes universitarios sobre la autoridad de los profesores, como cuestión problemática en la escena pedagógica contemporánea. Específicamente, sitúa su indagación en relatos de estudiantes próximos a finalizar sus estudios de grado en tres carreras paradigmáticas dentro de las profesiones liberales, las ciencias exactas y las humanidades: contador público, licenciatura en física y licenciatura en letras. Optando por una metodología de tipo cualitativa, se priorizó la técnica de la entrevista semiestructurada. En el análisis de los relatos se reconstruyen las formas en que los estudiantes interpretan la cuestión de la autoridad, considerando procesos de autorización y reconocimiento de los profesores, como así también expresiones de desacreditación. Se consideran, por último, algunas de las particularidades de estos procesos según las carreras de pertenencia.

\section{PALABRAS CLAVE}

autoridad; universidad; profesores; estudiantes. 


\title{
THE AUTHORITY OF THE TEACHERS FROM THE STUDENTS' PERSPECTIVE
}

\begin{abstract}
This paper shows the results obtained from research centered on exploring the views of university students regarding the authority of teachers as a problematic area in the contemporary pedagogical scene. Specifically, it places its inquiry on reports of students finish their graduation studies in three paradigmatic careers in the science and humanities professions: public accountant, physics and the teaching of literature. Opting for a qualitative methodology, the technique of semi-structured interviews was prioritized. In the analysis of the reports, the ways in which students see the question of authority were reconstructed, considering both authorization processes and recognition of teachers, as well as expressions of disbelief. Finally, some of the particularities of these processes are considered as relating to the teachers' careers.
\end{abstract}

\section{KEYWORDS}

authority; university; teachers; students.

\section{A AUTORIDADE DOS PROFESSORES PELA PERSPECTIVA DO ALUNO}

\section{RESUMO}

Este artigo discute os resultados obtidos nas pesquisas focadas em explorar as opiniões dos estudantes universitários sobre a autoridade dos professores como questão problemática no cenário educacional contemporâneo. Especificamente, situa sua indagação em relatos de estudantes próximos a concluir os estudos de graduação em três carreiras paradigmáticas dentro das profissões liberais, das ciências exatas e das humanidades: contador público, licenciatura em física e licenciatura em letras. Optando por uma metodologia de tipo qualitativa, priorizou-se a técnica da entrevista semiestruturada. $\mathrm{Na}$ análise dos relatos, reconstroem-se as formas por meio das quais os estudantes interpretam a questão da autoridade, considerando processos da autorização e reconhecimento dos professores, assim como expressões de descrédito. Consideram-se, por último, algumas das particularidades desses processos tendo em conta as carreiras a que pertencem.

\section{PALAVRAS-CHAVE}

autoridade; universidade; professores; estudantes. 


\section{INTRODUCCIÓN}

El tema de la autoridad ha dado lugar durante la última década a una serie de interrogantes y preocupaciones, en un contexto de transformaciones de las instituciones de la modernidad. Por un lado, se afirma que las nuevas generaciones carecen de referentes con los cuales identificarse, de figuras de autoridad que asuman la tarea de orientarlas. Pero también se señala lo contrario, que la autoridad no ha desaparecido sino que se ha transformado, multiplicándose los referentes autorizados y generándose nuevas formas de regulación social, nuevos principios y prácticas legitimados y, en consecuencia, nuevas experiencias subjetivas y culturales.

En el campo de los estudios educativos se ha intervenido en dichos debates, se ha señalado el carácter necesario de la autoridad en las relaciones pedagógicas y la necesidad de volver a pensarla, cuestionando los modos tradicionales de ejercerla. Pero esto ha tenido relevancia en investigaciones exclusivamente teóricas o centradas en los niveles primario y medio del sistema educativo. Sin embargo, no encontramos un desarrollo similar en los trabajos que toman a la universidad como objeto de investigación. Y en los casos en que se lo aborda se prioriza un enfoque organizacional, teniendo en cuenta principalmente la clasificación en niveles y tipos de autoridad realizada por Burton Clark (1983). ${ }^{1}$

A partir de encontrar una vacancia en esta área, en el presente artículo presentamos algunas conclusiones de un trabajo de investigación centrado en explorar las visiones sobre la autoridad de los profesores, teniendo como referencia relatos de estudiantes próximos a finalizar sus estudios de grado en la Universidad Nacional de Rosario (UNR ). ${ }^{2}$ Esta institución cuenta con doce facultades dispersas en la ciudad y zonas aledañas y con una matrícula de aproximadamente 73 mil

1 El autor considera la existencia de seis niveles de autoridad -de la base hacia la cúpula- y aclara que estos no se encuentran en todos los sistemas. El primer nivel es el departamento -más frecuente en los Estados Unidos- o la combinación de la cátedra con el instituto, propia del ampliamente imitado modelo europeo. El segundo nivel es un agregado de las unidades y funciones operativas enmarcadas en un establecimiento: la facultad. El tercer nivel es la universidad o el college; institución circunscrita a una localidad que incorpora unidades operativas y facultades. El cuarto nivel consiste en la administración académica que comprende varios campus (universidades federadas, subsistemas regionales o estatales, consejos de rectores, etc.). El quinto nivel corresponde al gobierno estatal, provincial o municipal, en el que la autoridad se concreta en un ministerio, departamento u oficina y se subordina el poder ejecutivo o legislativo. E1 sexto y último corresponde al gobierno nacional. En relación con estos niveles Clark identifica seis formas de autoridad. Las tres primeras están basadas en la disciplina: autoridad personalista (profesoral), autoridad colegiada (profesoral) y autoridad profesional. Las siguientes están basadas en el establecimiento: autoridad del patronato (institucional) y autoridad burocrática (institucional). Por último, como forma de autoridad basada en el sistema, refiere a la autoridad burocrática (gubernamental). (Clark, 1983).

2 La investigación sobre la cual se basa este artículo dio como resultado la tesis doctoral realizada a partir de becas del Consejo Nacional de Investigaciones Científicas y Técnicas (CONICET), titulada Figuras de la autoridad y transmisión del conocimiento universitario. Un estudio centrado en relatos de la experiencia estudiantil en la Universidad 
estudiantes, lo que la ubica -luego de Buenos Aires, Córdoba y La Plata-entre las universidades más grandes de Argentina.

Luego de realizar un relevamiento en todas las facultades de la UNR, focalizamos la indagación en tres de ellas: ciencias económicas y estadística, ciencias exactas, ingeniería y agrimensura y humanidades y artes, considerando específicamente las carreras de contador público, licenciatura en física y licenciatura y profesorado en letras. La selección de las carreras se justifica teniendo en cuenta, fundamentalmente, las tradiciones disciplinarias en las cuales se inscriben. Siguiendo la clasificación de Becher (2001), física y letras constituyen campos muy consolidados entre las ciencias exactas o "duras puras", en el primer caso, y las humanidades o ciencias "blandas puras", en el segundo. En el caso de contador público, se consideró su perfil como carrera de orientación liberal y profesional. Asimismo, las diferencias en el plano de los estilos de docencia, los modos de regulación de la vida cotidiana estudiantil y los encuadres en torno a los cuales se desarrolla la tarea pedagógica también contribuyeron en esta decisión.

Organizamos este artículo del siguiente modo: el primer apartado se detiene en los aspectos metodológicos de la investigación, explicitando las técnicas de recolección de datos y los procedimientos analíticos priorizados. Luego se explicita brevemente la perspectiva teórica adoptada, dando cuenta de la articulación entre los conceptos de autoridad y reconocimiento. Por último, se presentan las conclusiones provisorias del trabajo.

\section{MATERIALES Y MÉTODOS}

El problema de esta investigación se configuró en una zona de diálogo entre diferentes disciplinas de las ciencias sociales. De este modo, la pedagogía, el psicoanálisis, la filosofía política, la filosofía de la educación, la sociología y la sociología del conocimiento ofrecieron aportes conceptuales a partir de los cuales construimos nuestro objeto.

Optando por una metodología de tipo cualitativa, el trabajo recupera algunos insumos del paradigma de la narrativa en las ciencias sociales, en tanto nos interesa principalmente analizar las visiones que los propios estudiantes atribuyen, en sus relatos orales, a las figuras de autoridad.

La construcción de nuestro objeto se organizó en torno al siguiente corpus:

- Revisión de bibliografía proveniente de las disciplinas mencionadas;

- Entrevistas semiestructuradas a estudiantes universitarios próximos a finalizar sus carreras de grado en la UNR;

- Entrevistas semiestructuradas a los directores de las carreras estudiadas, a los fines de tener en cuenta aspectos relevantes de la dinámica institucional

Nacional de Rosario. Doctorado en Ciencias Sociales, Facultad de Ciencias Sociales UBA. Año 2012. Directora: doctora Sandra Carli. 
y del encuadre general en que transcurre el proceso de formación universitaria;

- Entrevistas semiestructuradas a profesores con amplia trayectoria en las carreras, con el objetivo de poder obtener mayores precisiones sobre aspectos propios de la cultura institucional y aclarar algunas cuestiones sobre las peculiaridades disciplinarias;

- Documentos de política educativa y política institucional: Ley de Educación Superior, Estatuto de la UNR, Actas de Consejo Directivo, etc.;

- Documentos sobre la historia de la UNR.

Cabe destacar, frente a este corpus, la centralidad de las entrevistas a los estudiantes. En este caso utilizamos la técnica de la entrevista semiestructurada con aportes de los relatos de vida (Bertaux, 2005).

Dicho tipo de entrevista facilita la comparación entre las respuestas y permite establecer recurrencias y diferencias discursivas en torno a los conflictos a relevar. Así, el diseño de un guión previo pretendió instalar las temáticas pertinentes sin dejar, por ello, de brindar flexibilidad para ordenar y reformular las preguntas a lo largo de la entrevista y en entrevistas posteriores.

El tipo de indagación que realizamos es retrospectiva y no longitudinal. Es decir, no seguimos una cohorte en el tiempo con la finalidad de observar sus trayectorias, sino que partimos de un presente determinado (los años 2009 y 2010) y desde allí orientamos las entrevistas hacia una recuperación de experiencias pasadas.

El trabajo de campo se llevó a cabo en dos instancias. En un primer momento, se centró en entrevistas a estudiantes de cada una de las facultades que componen la UNR. Esta primera indagación -compuesta de un corpus de 15 entrevistas- no sólo nos aportó datos para realizar nuestros primeros ajustes teóricos, confrontando así el marco conceptual indagado con las categorías de los entrevistados, sino que además fue crucial en el proceso de selección de las carreras que focalizaríamos. En un segundo momento, considerando criterios de saturación teórica (Glaser; Strauss, 1967), realizamos 45 entrevistas a estudiantes de las carreras de física, letras y contador público: 22 mujeres y 23 varones, cuyas edades oscilan entre los 23 y los 26 años. Con algunos de los entrevistados/as realizamos una segunda entrevista, con fines de aclarar, ampliar y/o profundizar ciertos contenidos surgidos en el primer encuentro.

Los entrevistados fueron seleccionados considerando, en primer lugar, que se encontraran transitando la etapa final de sus carreras universitarias. En algunos casos, al concretarse el segundo encuentro, los jóvenes ya se encontraban graduados. Esto ocurrió fundamentalmente con los estudiantes de Física, carrera en la cual el apremio por ingresar al sistema científico los insta a finalizar los estudios de grado en el tiempo requerido por el plan de estudios. Prestamos atención, asimismo, a abarcar diferentes perfiles de estudiantes, por lo cual tuvimos en cuenta a jóvenes provenientes de localidades pequeñas y de la ciudad de Rosario; a aquellos que cursaron sus estudios secundarios en escuelas públicas y privadas; a militantes de agrupaciones políticas estudiantiles y a quienes transitaron sus estudios universitarios sin participar en dichas agrupaciones. De este modo, pudimos acceder a relatos que expresan diferentes experiencias de socialización y de formación. 


\section{AUTORIDAD Y RECONOCIMIENTO: UNA ARTICULACIÓN NECESARIA}

Cuando hablamos de "autoridad", estamos ante una de esas nociones sobre las cuales todos tenemos alguna idea pero que no resulta simple definir. Muchas veces se la asimila a la noción de poder, otras tantas a la de dominación y en ocasiones a la violencia. Se la utiliza para hablar de relaciones habilitantes, centradas en el respeto y la admiración, como de aquellas situaciones en las que imperan rasgos arbitrarios. Se la asocia al temor y a la habilitación, a la autorización y al autoritarismo.

Para desentrañar esa complejidad -que puede asumir la forma de paradoja-y aportar algunas características distintivas de este fenómeno, desde diferentes líneas teóricas se ha hecho hincapié en las operaciones de credibilidad y reconocimiento inherentes al acto de autorizar (De Certeau, 2006; Kojève, 2004; Ricoeur, 2008).

$\mathrm{Al}$ plantear que no existe autoridad que no sea reconocida por otros se produce una doble operación: por un lado se atempera la idea de dominación o de ejercicio arbitrario del poder con las cuales suele asociársela; por otro, la articulación entre autoridad y reconocimiento y la idea de relación en ella implicada, se aleja de la pretensión de encontrar definiciones esencialistas. Es así que desde esta perspectiva, lejos de considerar a la autoridad como una sustancia localizada en un sujeto particular, una posesión de hecho, se la articula con procesos de validación o autorización que son exteriores a ella misma. En otras palabras, la autoridad no implica principios en sí mismos, sino atributos, cualidades, rasgos reconocidos. Se necesita, por ende, el reconocimiento, la creencia, la confianza para que alguien se constituya -para otro u otros- en autoridad; y en este sentido, las interpretaciones $\mathrm{y}$ reacciones de estos otros ocupan un lugar central.

Ahora bien, esos principios reconocidos no dependen sólo de los intereses de los sujetos. Por el contrario, asumen cierta regularidad en función de los sistemas de creencia que se van configurando en los diferentes espacios sociales e institucionales.

En relación con lo anterior, durante mucho tiempo fue posible identificar, en el campo de la educación, una serie de rasgos asociados a las figuras de autoridad. Entre ellos, ocuparon un lugar fundamental la permanencia en el tiempo y el "saber más"; o en otras palabras, la experiencia y el conocimiento. Rasgos esos que van a presentar claros signos de transformación en las sociedades contemporáneas en general y en las instituciones de educación superior, en particular.

Cabe señalar, sin pretensiones de exhaustividad, algunos fenómenos que están en la base de dicha transformación. En primer lugar, las posiciones antiautoritarias y antiinstitucionales (surgidas a mediados del siglo XX) a partir de las cuales se aboga por la disolución de las jerarquías, van a dar lugar a un ciclo en el que la autoridad tiene que validarse y justificarse constantemente (Dussel; Southwell, 2009) y en el que experiencia y autoridad quedan dislocadas. De este modo se refería Agamben en la década de 1970 en un texto hoy clásico, Infancia e historia:

La experiencia no tiene su correlato necesario en el conocimiento, sino en la autoridad, es decir, en la palabra y el relato. Actualmente ya nadie parece disponer de autoridad suficiente para garantizar una experiencia y, si dispone de ella, ni siquiera es rozado por la idea de basar en una experiencia el fundamento 
de su propia autoridad. Por el contrario, lo que caracteriza al tiempo presente es que toda autoridad se fundamenta en lo inexperimentable y nadie podría aceptar como válida una autoridad cuyo único título de legitimación fuese una experiencia. (El rechazo a las razones de la experiencia de parte de los movimientos juveniles es una prueba elocuente de ello). (Agamben, 2007, p. 9-10)

Las transformaciones sociales y culturales propias de las últimas décadas del siglo XX indican, por su parte, procesos de individualización que ponen en tensión la noción misma de autoridad centrada en la transmisión cultural, apareciendo el sujeto cada vez más como una especie de soberano "autorrealizado" que parecería no disponer de experiencias transmitidas contra las cuales revelarse. Es así que la búsqueda de referentes y el reclamo de autoridades que se hagan cargo de las responsabilidades asumidas, están a la orden del día. Principalmente entre los jóvenes, se observan no sólo expresiones de desacreditación de las autoridades sino también una demanda de regulación que se encuentra estrechamente vinculada tanto a la percepción de cierta indiferencia por parte de los referentes del mundo adulto y a fenómenos de autonomía temprana, como a la prolongación de la heteronomía en edades avanzadas. En este sentido, desde la perspectiva de Zizek (2007), el problema actual en relación con la autoridad parecería no radicar en la autoridad -patriarcal- y en la lucha para emanciparse de ella, sino en las nuevas formas de dependencia provocadas por su declinación.

Desde un registro sociológico y focalizando su mirada en las instituciones educativas contemporáneas, Dubet (2006) también va a referirse a los procesos de resignificación de la autoridad visibles en dichos espacios. Este autor plantea el pasaje de formas de autoridad sostenidas por instancias exteriores autorizadas (valores universales, normas, posiciones consagradas, etc.) a otras en las cuales la personalidad de los sujetos -y específicamente de los docentes- ocupa un lugar privilegiado. En estos términos, la autoridad profesoral parece provenir más del sujeto en su carácter de ejecutor de una performance determinada, que como actor inmerso en una trama institucional y sostenido por ella, lo cual implica formas de autoridad más inciertas y sujetas a la negociación de las partes involucradas. En ese contexto, la participación de los sujetos cobra cada vez mayor relevancia en la construcción de sus trayectorias. Estamos ante identidades sociales menos unitarias, en menor medida definidas en relación con instancias totalizadoras y con el aprendizaje de roles propuestos; por ende, más disponibles a las experiencias singulares.

\section{EXPERIENCIAS ESTUDIANTILES EN RELACIÓN CON LA AUTORIDAD DE LOS PROFESORES}

Cuando hablamos de experiencias estudiantiles, adquiere particular relevancia el lugar de los relatos, recuperados en este caso mediante las entrevistas. Desde la perspectiva que nos interesa, "la experiencia existe en el proceso mismo de la producción de sentido"(Link, 2006). No remite a "lo que pasa" en general, sino a lo que "le" pasa a alguien en singular, y eso que a uno le pasa es indisociable de la forma 
en que lo expresa, en que lo describe (Larrosa, 2003); pero también "indisociable" del modo en que elabora en el presente aquello que le sucedió en el pasado y que define una trayectoria.

Lo anterior no implica una indiferenciación entre la temporalidad de los acontecimientos y la temporalidad del relato; o, en términos de Ricoeur (1996), "el tiempo de la vida, del acontecer y el tiempo de la narración”, pero sí tiene el valor de afirmar la imposibilidad de acceder a una experiencia por fuera de aquello que la constituye, es decir, el lenguaje que la nombra.

Es atendiendo a esto último que consideramos necesario, en algunos momentos, transcribir textualmente ciertos fragmentos de entrevistas que consideramos significativos. Estos remiten a las experiencias singulares de algunos sujetos pero tienen el valor de condensar una serie de sentidos que se presentaron recurrentemente en la investigación.

Recapitulando el recorrido realizado pudimos arribar a algunas conclusiones provisorias que, sucintamente, presentamos a continuación:

1) El fenómeno de la autoridad se presenta de modo ambivalente. Es decir, la noción de autoridad es utilizada para hacer referencia a los profesores reconocidos como referentes en el plano de la formación, docentes que habilitaron el aprendizaje y la producción de pensamiento, como a aquellas figuras caracterizadas por imponer temor y producir sentimientos de inhabilitación. En relación con la primera acepción es significativo el siguiente fragmento de entrevista:

Con este tipo vos te encontrabas con algo groso, yo nunca había tenido un docente así. Un tipo que podés respetar más o menos, pero como dijo él en un seminario: hay una precondición para el aprendizaje, que es que vos le reconozcas una autoridad al tipo que te va a enseñar. ${ }^{3}$

Personas "grosas", "maestros", "genios”, “capos”; estas palabras ocuparon un lugar central en los relatos para caracterizar a ciertas figuras autorizadas.

En contraposición, la noción de autoridad también fue utilizada para hablar de relaciones intersubjetivas signadas por la violencia o el maltrato: los profesores "mandones" que, desde la perspectiva de los estudiantes, utilizan su posición dentro de la institución para ejercer su poder.

En este sentido, muchas de las manifestaciones e intervenciones que los profesores consideran propias de las responsabilidades implicadas en el rol, devienen para los estudiantes expresiones diversas del maltrato. Maltrato que sólo presenta cierta cercanía con la autoridad cuando aquellas personas de las que proviene se encuentran previamente reconocidas; es decir, cuando ya ha recaído sobre ellas la eficacia simbólica de la creencia.

Asimismo, tal como se pone de manifiesto en la siguiente cita, suele suceder que el concepto de autoridad sea asimilado al de violencia:

3 La palabra groso se utiliza frecuentemente en Argentina para expresar la idea de algo grande, importante, bueno. 
- Vos me decías la problemática de la violencia cuando hablamos, ¿no?, me parece, o algo así...

- De la autoridad...

- Sí, de la autoridad. Yo lo relacioné más con lo violento de algunos profesores.

En el $1^{\circ}$ año común leímos un texto que se llama "La violencia que no se ve". Bueno, ese texto es muy interesante, habla de la violencia que no se ve. La violencia que se ve es cuando una mujer es golpeada, digamos, la violencia física. Hay otra violencia que no se ve. Por ejemplo, que un profesor te diga que va a venir a una consulta y no viene, eso es violencia. Que una clase tiene que empezar a una hora y no empieza, eso te genera violencia.

La autoridad y su articulación con la violencia pueden estar aludiendo a formas del trato, a faltas de responsabilidad, a intervenciones profesorales no legitimadas desde el punto de vista estudiantil. ${ }^{4}$

Es así que la ambivalencia permite identificar fenómenos de autorización del otro al mismo tiempo que escenas de desautorización. Estas últimas tienen lugar fundamentalmente cuando se sienten "violentados" (fenómeno que en el contexto antijerárquico del presente abarca cada vez más situaciones), pero también cuando descubren que el profesor no sabe aquello que intenta transmitir, cuando se encuentran ante la situación de tener que enseñarles algo a sus docentes o cuando sienten que el respeto o el reconocimiento no es algo recíproco. Decía una joven entrevistada:

Si no te ganan, vos no los reconocés. Es difícil si no le das autoridad a alguien, sos un poco escéptica [...] He escuchado decir barbaridades que socavan su autoridad [...] Yo tendría que poder ponerla por encima de mí y no puedo. No puedo creer que diga lo que diga con esa formación.

2) Los estudiantes interpretan a la autoridad como una relación entre posiciones desiguales, que puede sostenerse como tal en la medida en que esté basada en el reconocimiento recíproco entre las partes y en tanto opere la creencia en la legitimidad de los fundamentos sobre los que se asienta la distinción.

De este principio general se derivan varias cuestiones. Por un lado, la idea de reciprocidad implica la pretensión de recibir algo a cambio de la delegación de autoridad: respeto, atención, reconocimiento; "Respeto al profesor si éste me

4 Cabe considerar aquí el modo en que sobre este tema se refería una profesora de la carrera de letras:

La palabra maltrato me ha perseguido desde que doy clases [...] Una vez, constatando que nadie leía planteé que un estudiante de letras al que no le gusta leer es como un estudiante de medicina al que le da asco la sangre. Después de eso, un grupo que se sintió afectado elevó una nota acusándome de haberlos maltratado. En otra oportunidad, en un examen planteé con todo cuidado: "estudiaste pero no comprendiste bien el tema”, y esta alumna elevó una nota a jurídica aduciendo maltrato. 
respeta, lo reconozco simbólicamente y en consecuencia le otorgo autoridad si el reconocimiento es recíproco", expresarían estos jóvenes. No se evidencia aquí un deseo de liberarse de las autoridades, sino una demanda de respeto y reconocimiento teñida del reclamo de ser tratados como iguales y de generar vínculos de confianza. Habría, de este modo, una impugnación de las relaciones jerárquicas, un reconocimiento de aquellos profesores que los tratan más en términos de paridad y que se colocan en el lugar de ser "uno más" en el plano vincular, pero una asimetría que sigue siendo necesaria en el plano del conocimiento.

Lo anterior en muchas ocasiones viene acompañado de una demanda de anular los signos que indican diferencias jerárquicas y del deseo de ser tratados "de igual a igual".

Así, la aceptación de una diferencia necesaria en el plano del conocimiento y su transmisión, se combina con una resistencia para admitir que dicha diferencia se traduzca bajo el significante de la superioridad. Y en este sentido se resaltan aquellas figuras que, portando un "saber" y un "saber hacer" que los vuelve distinguidos, se las ingenian para ocultar las marcas o los signos de su posición en el trato con los demás. Todo parece indicar que, tal como afirma Sennett (2003), la ratificación de la desigualdad ofende a las sensibilidades de nuestros tiempos.

Por otro lado, los estudiantes militantes afirman relacionarse de otro modo con los docentes en el plano de lo político, donde existe una puja de poder entre grupos corporativos y se dan vínculos más simétricos, en tanto las posiciones están centradas en la lógica de la representación y no ya en la posesión de determinados objetos de conocimiento.

3) Vemos que el "saber más" o la experiencia no desaparecen como fundamentos de la autoridad de los profesores (estos son centrales sobre todo en la universidad), pero al mismo tiempo tiene lugar cierta impugnación de la antigüedad como criterio para la permanencia de los profesores en sus cargos. Es decir, si bien se observa una valoración del saber obtenido a través del paso del tiempo, se detectan también críticas relativas a la falta de adecuación de los docentes a los cambios tecnológicos o al cansancio percibido en algunos profesores. No habría planteos esencialistas sino juicios críticos, situados, en los que obtiene reconocimiento tanto aquel profesor "viejo" que "forma escuela", que deja un legado, como aquellos jóvenes entusiastas que, pese a tener cargos simples o no rentados, se comprometen con la tarea.

Desde la perspectiva de los estudiantes, no siempre las posiciones de poder ocupadas por sus docentes (manifestadas principalmente en los cargos y dedicaciones) tienen un correlato en el mérito de éstos. La impugnación de los profesores como no merecedores de ocupar dichos lugares se asienta, en general, sobre la base de nociones meritocráticas, que son las que priman en los concursos docentes.

El relato que sigue, proveniente de una entrevista a un estudiante de Contador Público, pone de manifiesto tanto el descrédito estudiantil respecto de ciertas personas en particular, como su escepticismo sobre la legitimidad de los mecanismos institucionales que regulan las formas de acceso a la carrera docente: 
Tendrían que ponerse las pilas con los profesores que ponen, yo no sé si es todo por concurso, pero hay muchos profesores que dejan mucho que desear y hay muchos profesores importantes que están ahí abajo que podrían ser jefes de cátedra. $^{5}$

Respecto de lo anterior, cabe tener en cuenta que en la universidad en la que se centró nuestro trabajo el porcentaje de docentes concursados es bajo. ${ }^{6}$ Frente a esto, podemos pensar que si el concurso brinda la posibilidad de legitimar a la autoridad profesoral sobre la idea de que quienes acceden a un cargo están calificados para el mismo, su escasa presencia plantea un serio desfasaje entre la autoridad institucional (como fuente de legitimidad para los que ejercen autoridad en su ámbito) y la autoridad simbólica (el poder de un enunciador para producir creencia) (Ricoeur,2008). Pensar esta doble perspectiva de la autoridad desde el punto de vista de los profesores, implica tener en cuenta dos fuentes de las que se nutre su autoridad: el nombramiento que hace la institución y sus propias intervenciones como docentes, basadas en el saber, en el saber hacer, en sus cualidades, estrategias, carisma, etc. En un contexto de "declive institucional"(Dubet,2006), esta última fuente adquiriría mayor envergadura. Es así que -como afirma Dubet-"le corresponde al profesor construir él mismo su autoridad movilizando aquello que, a falta de otro concepto llamamos su personalidad"(Dubet, 2007, p. 57).

4) En estrecha relación con el punto precedente, vemos que la personalidad de los profesores es un aspecto de peso en el proceso de delegación de su autoridad. En esta clave, la autoridad no es definida en términos de imposición sino de seducción. Esto se expresa en los relatos de los estudiantes a través de términos como "motivación", "enganche”, docentes "copados", "piolas". ${ }^{7}$ También se pone de manifiesto en los modos en que se habla acerca del "saber enseñar", como siendo esto algo individual, una especie de "don" o talento que sólo algunos profesores poseerían. Es común, en este sentido, que se piense a la autoridad en términos individuales, como siendo un atributo que poseen o carecen algunas personas en particular, dejando de considerar que, en general, los individuos actúan como soportes de determinadas instituciones.

5 La expresión ponerse las pilas se utiliza en algunos países latinoamericanos en referencia a la idea de afrontar un asunto determinado con esfuerzo, dedicación, energía.

6 Según el último dato obtenido, correspondiente al año 2009, en la UNR sólo el 39,2 $\%$ de los docentes está concursado. Si este dato se desagrega entre profesores (titulares, asociados y adjuntos) y auxiliares de docencia (jefes de trabajos prácticos), se desprende $43,7 \%$ en el primer caso y $35,9 \%$ en el segundo.

Fuente: Informe de evaluación externa del Comité de pares de la CONEAU, febrero de 2009. Disponible en: <http://www.coneau.edu.ar/archivos/evaluacion/UNR.pdf〉. Acesso en: 10 mar. 2009.

7 Estas expresiones se utilizan en algunos países y se refieren a: "enganche": sentirse atraído por alguien o algo; "copado": término que se usa a menudo entre los jóvenes para decir que algo es muy bueno; "piola": en el contexto de la frase, la expresión "docentes piolas" se utiliza para caracterizar a docentes amables, agradables, simpáticos, etc. 
Nos interesa señalar que en la medida en que la actividad de los profesores está basada en gran parte en una cuestión enunciativa o discursiva, la cuestión de la personalidad y del carisma siempre ha sido componente a tener en cuenta a la hora de hacer referencia a su autoridad, más allá de la legitimidad que puede dar el rol ocupado. Ahora bien, creemos que -como planteamos en el punto anterior siguiendo a Dubet-la fuerza del carisma tiende a aumentar, como fundamento de la autoridad, cuando las instancias exteriores muestran signos de debilidad. Esto implica formas de legitimidad más inciertas, desprovistas del apuntalamiento de la autoridad institucional y, por ende, más sujetas a la negociación entre las partes involucradas.

5) La autoridad es interpretada por los estudiantes no como algo que los profesores poseerían producto de su investidura, sino como aquello que adviene tras un proceso de lucha por ella. La noción de "ganancia"-propia de un juego, de una batalla o de una inversión económica- nos recuerda la fecundidad de la noción bourdiana de "campo". Como en todo campo, en la universidad se ponen en juego diferentes intereses y aquel que sale a jugar invierte en él las "fichas" para poder conservar o transformar su posición en una red de relaciones. La disputa en torno al capital simbólico en cuestión (y en ocasiones también respecto del capital económico) colocaría a los miembros de cada campo en posiciones diferenciadas según el prestigio y reconocimiento alcanzados (Bourdieu, 2006).

Por parte de los estudiantes, la posición de los profesores dentro del campo sería interpretada en ocasiones como una cuestión de peso. En este sentido, aquellos profesores que ya cuentan con cierto reconocimiento entre los pares entrarían a las aulas con un cierto "plus" de autoridad ya adquirida, o más precisamente "ya ganada".

Pero en la mayoría de los casos los estudiantes pondrían más énfasis en las disposiciones de los sujetos para lograr la autoridad que en la propia posición de estos en el campo.

No obstante esto, no sólo el carisma y la personalidad son atributos destacados. Así, tendrían muchas chances de ganar la autoridad quienes expresan un conocimiento cabal de los temas a tratar y un saber acerca de su transmisión. Los estudiantes interpretan el saber sobre la enseñanza, el sentido práctico de las estrategias puestas en juego en la transmisión, y la relación establecida con ellos como sujetos en ese intercambio pedagógico, como un aspecto clave en las figuras autorizadas. Aquí se pone en juego, entonces, además de un saber conceptual, una experticia docente que va a estar en el centro de las críticas hacia aquellos profesores que no tendrían en cuenta este aspecto como importante en la enseñanza universitaria.

A continuación, realizaremos una síntesis de las conclusiones a las que arribamos al considerar los relatos de los estudiantes de cada una de las instituciones en las que se centró nuestro estudio. 


\section{PECULIARIDADES DE LAS VISIONES SOBRE LA AUTORIDAD EN FUNCIÓN DE LAS CARRERAS DE PERTENENCIA}

1 - En el caso de la carrera de contador público observamos:

- La sensación de ser un número, de no ser reconocido, contrasta frente a la familiaridad en el tipo de vínculo propio del colegio secundario. En una facultad masiva como es ciencias económicas, con una cultura institucional de gran despersonalización pero en la que se evidencian esfuerzos institucionales por generar otro tipo de vínculos, adquiere centralidad el significante "contención".

En el discurso social de la época, la noción de “contención” ocupa un lugar privilegiado. De uso frecuente en el lenguaje de la psicoterapia, que por su parte en los últimos años ha adquirido relevancia en los diferentes niveles del sistema educativo incluido el universitario remite a la idea de sostener, comprender al otro, apoyar, pero también hace referencia a acotar, sujetar, limitar.

Ecclestone y Hayes (2008) se explayan sobre esta tendencia a nivel mundial a priorizar la cuestión de las emociones y los sentimientos en todos los niveles del sistema educativo, desde la primaria hasta la universidad, destacando cómo los principios de la psicoterapia se aplican en el campo educativo. Por su parte, Abramowski (2010) ha señalado la centralidad adquirida por la cuestión afectiva en relación con los vínculos entre maestros y alumnos.

Estas cuestiones pueden vincularse con la primacía que en el campo de la educación han adquirido, desde hace algunas décadas, las pedagogías psicológicas. Pero en la legitimidad adquirida por el terreno emocional y afectivo de los sujetos confluyen también discursos político-pedagógicos de la diferencia, del multiculturalismo, del compromiso político de la docencia, hasta psicologías liberales y literatura de autoayuda (Dussel, 2010).

Dichos discursos no son ajenos a las percepciones de los estudiantes y a los modos en que despliegan su reflexividad respecto de experiencias pedagógicas presentes y pasadas.

Ahora bien, los usos que estos jóvenes hacen del término "contención” se encuentran permanentemente articulados con la noción de reconocimiento. Así, ser reconocido en este nuevo espacio simbólico que en un principio puede evocar imágenes ligadas a la hostilidad frente al no iniciado en las reglas del juego, potencia sentimientos de inclusión y pertenencia. En las referencias sobre este punto sobresale la figura del par, de algunos profesores y, en algunos casos, de los tutores.

Si bien las valoraciones respecto de las tutorías presentaron diferencias, en la medida en que muchos se encontraron decepcionados por haber creído que allí iban a poder saldar la brecha entre el secundario y la universidad en materia de contenidos, para otros estas representaron experiencias positivas. Fundamentalmente, porque encontraron en los tutores una representación subjetiva de la Facultad. Esto mismo fue destacado respecto de los programas de apoyo que se ofrecen para apuntalar a quienes se encuentran rezagados. 
- Una notoria asociación entre la autoridad y el respeto. Es a través de esta noción como los estudiantes de la carrera de contador público hacen referencia a la necesidad de reconocimiento recíproco inherente a la autoridad. Así, el respeto mutuo, en sus diversas manifestaciones, es lo que permite sostener un vínculo asimétrico que, de no estar atravesado por este, es asociado fácilmente a una relación entre fuerzas desiguales e ilegítimas.

La dimensión vertical asociada a la oposición entre alto y bajo, superior e inferior, parece contrastar con la dimensión horizontal del reconocimiento en el plano de la estima de sí. Es así que junto con las cualidades de un "buen docente" (e1/la que organiza las clases, explica la cantidad de veces que sean necesarias, no se irrita cuando es interrogado/a, establece dispositivos de relación entre la teoría y la práctica, da cuenta de algunos aspectos propios de la profesión), se destaca en el reconocimiento de los profesores aquellos atributos de la personalidad centrados en acortar las distancias jerárquicas: "profesores accesibles", "relaciones cómodas", "vínculos cercanos", tratamiento de "estudiante a estudiante", "que te traten como uno más".

La situación en la que ese respeto recíproco pareciera quedar más debilitada es en el examen oral, instancia percibida por los estudiantes como radicalmente asimétrica y proclive a la arbitrariedad en los juicios de valor.

Si hay una palabra recurrente a la hora de hablar de los exámenes orales, esta es "miedo". ¿En qué reside ese miedo? Fundamentalmente, se habla de un temor a quedar expuestos en lo que no se sabe y se supone que se tendría que saber, inadecuación que derivaría en un "maltrato" y que generaría sentimientos de vergüenza.

Las escenas de estudiantes reclamando por injusticias en relación con los exámenes no son exclusivas de esta época. Ahora bien, creemos que un rasgo característico de estos últimos años es el tipo de discurso utilizado por los propios estudiantes para referirse a lo que sienten luego de haber obtenido una baja calificación. Abundan expresiones asociadas a los discursos psicológicos o de la psicoterapia. Se habla de debilitación de la autoestima, de sensaciones de inseguridad, de pérdida del amor propio. Asimismo, el hecho de que un aspecto de su desempeño académico sea puesto en cuestión es considerado un profundo agravio sobre su propia personalidad.

- Aquellos docentes que son vistos como portando una "vocación de enseñar" son los que generarían mecanismos de contención frente a la impersonalidad. Partiendo del dato que la mayoría de los profesores no practica la docencia como actividad laboral principal, dadora de sustento material, obtienen reconocimiento quienes, aun sin necesitarlo como medio de subsistencia, asisten a clases y se comprometen con la tarea. El hecho de que la docencia no adquiera para ellos el estatuto de trabajo y aun así se realice con responsabilidad, es motivo de admiración. La idea de "vocación" condensa una serie de figuras de profesores reconocidos por los estudiantes como "desinteresados", "laboriosos" o "talentosos", a quienes se les confiere 
autoridad no sólo por considerarlos referentes desde una perspectiva profesional, sino en materia de enseñanza.

2 - Respecto de los estudiantes de física:

- La experiencia de formación de estos jóvenes se halla en las antípodas de la de los estudiantes impersonalizados de las facultades masivas. En este caso, al ser física una carrera de matrícula reducida, los jóvenes destacan los vínculos más cercanos mantenidos con sus docentes.

- Figuras de autoridad asociadas con el cuidado de los estudiantes facilitarían la permanencia en una institución visualizada en una primera instancia como una familia que protege a sus integrantes. En este sentido, los estudiantes recuerdan especialmente a aquellos profesores que les transmitieron desde los inicios de la carrera ciertas pautas para formar parte de la comunidad científica. La imagen del físico que recibe y aloja a los recién llegados pone de manifiesto la fuerza que la hospitalidad de los "viejos" tiene en el afianzamiento de un sentido de pertenencia a la institución por parte de los "nuevos".

- La complejidad del objeto de conocimiento reconocida por los estudiantes los lleva a valorar a aquellos profesores capaces de acortar las distancias entre los temas y su capacidad de comprenderlos, quienes se esfuerzan por presentar diferentes argumentos y ejemplificaciones. Es así que la noción de "compromiso" -compromiso con el estudiante, compromiso con la enseñanza- asume una posición estelar en la diferenciación entre figuras profesorales.

Ahora bien, la figura del profesor "comprometido con la enseñanza" remite a una tensión que es constitutiva de la profesión académica en general pero que se expresa particularmente en este caso: el delicado equilibrio entre las tareas de docencia y la investigación. Sobre este punto se establecen diferencias entre aquellos profesores que enseñan como una tarea más de las implicadas en su condición de académicos e investigadores -como parte de los créditos necesarios en esa carrera-y aquellos profesores que "dejan un legado" o "forman escuela".

Los estudiantes establecen, entonces, una línea de demarcación entre profesores. Por un lado estarían quienes se esfuerzan por revalidar posiciones de autoridad en el campo científico, en el que, como ha sido ampliamente estudiado, es la evaluación de los pares acerca de la producción en investigación y no la transmisión del conocimiento la que ocupa un lugar central; por otro, aquellos docentes investidos como autoridades en el campo de la enseñanza.

- Teniendo en cuenta que los estudiantes de física se incorporan a equipos de investigación generalmente antes de finalizar sus carreras de grado, las reflexiones sobre los profesores se van articulando en las entrevistas con las referencias a los directores de equipo. 
Es así que en los diferentes espacios de trabajo los estudiantes detectan distintos modos de ejercer la autoridad por parte de sus superiores, los que guardan relación con las características que Sennett (2009) encuentra en los laboratorios modernos. En algunos se dispone de escasos rituales de unión entre los participantes y el trabajo se percibe como fragmentado, dificultándose la comprensión integral de los problemas y técnicas en torno a los cuales se está trabajando; otros se organizan en función de ritmos de trabajo bajo la autoridad del maestro, pero en un ámbito de reafirmación de la sociabilidad (idem). En estos últimos casos, quien hace de docente ayuda a los jóvenes a realizar técnicas, les enseña cómo hacerlas, muchas veces mostrándolo, sin instrucciones detalladas. Luego de una etapa de acompañamiento, irá retirando su apoyo habilitando al aprendiz para que pueda realizarlas autónomamente, lo cual no implica que este no siga dependiendo del maestro en el momento de interpretar los resultados.

Allí la autoridad es otorgada a partir del reconocimiento en el otro de una serie de disposiciones. Se admite estar trabajando con alguien que sabe más porque leyó más, está al tanto de los trabajos que se desarrollaron en el área. Esa experiencia le aporta un conocimiento tácito que no siempre puede traducirse en instrucción y, entonces, gran parte de su autoridad la obtienen de "ver lo que otros no ven, de saber lo que otros no saben" (idem, p. 102).

Si rechaza algún modelo de interpretación realizado por quien se está formando, puede argumentar sus razones. Adquirir una técnica requiere tiempo y el hecho de estar permanentemente ejercitándose en torno a ello, realizando mediciones, etc. puede llevar a que los jóvenes realicen el trabajo más rápidamente que el director. Sin embargo, ellos saben que en la instancia final necesitan los aportes de su conocimiento, experiencia y pericia. Y es así que cuando el estudiante alcanza intuiciones acertadas, él mismo suele reconocerlas como efecto de un acto de transmisión por parte del superior.

3 - En el caso de los estudiantes de letras:

- Junto con la posesión de conocimientos se destaca el tema de la pasión. Reconocer en los profesores una pasión por el objeto de estudio y por su transmisión es algo que, según algunos estudiantes, genera efectos en cadena, produce sujetos apasionados por la literatura. En este sentido, los profesores autorizados son aquellos que, en función de su representación (con todos los elementos de lo teatral implícitos en ella) hacen de la clase una experiencia estética, una experiencia en torno a la transmisión y apropiación de algo bello. Decía una estudiante:

Uno admira mucho a algunos profesores... en las clases a mí me hacían poner la piel de gallina. Te lo juro, yo salía de esas clases y tenía ganas de romper la vidriera de Ross y llevarme todos los libros a mi casa. ${ }^{8}$

8 Ross es una librería tradicional de la ciudad de Rosario y está ubicada a pocos metros de la Facultad de Humanidades y Artes. 
En relación con lo anterior, algunas de estas figuras de autoridad caracterizadas por la pasión y por ciertas cualidades histriónicas, son cuestionadas por hacer de la clase una conferencia en la que dejan fluir su saber y su pasión por el objeto sin atender a la modalidad de relación con los sujetos, es decir, excluyéndolos de su interlocución, de modo tal que la clase es considerada un monólogo. En estos casos, lo que queda desacreditado es la condición docente de ese académico sabio.

- Una fuente de autoridad importante es el reconocimiento obtenido por los profesores en el campo académico, el prestigio aportado por su desempeño en actividades que exceden a la enseñanza. La posición autoral de los profesores se enlaza con el reconocimiento de la experiencia, con el bagaje de lecturas y la capacidad de actualizar en las clases una trayectoria académica. Pero es, también, una cuestión a considerar el apuntalamiento de otros agentes externos a la escena del aula. En efecto, los reconocimientos en ámbitos académicos nacionales e internacionales impactan sobre las valoraciones estudiantiles. Se pondría en juego, aquí, la autoridad ligada tanto a lo realizado previamente como a su reactivación en el presente, la exterioridad como garante de la sabiduría de ese sujeto y la posibilidad de este de acreditarse, de autorizarse en cada encuentro.

Pero también, la autoridad localizada en la autoría -ya no de los profesores, sino de los autores que se toman como referencias en las materias- produce otras operaciones en la experiencia estudiantil. La referencia permanente a las críticas literarias autorizadas -reflejada en el uso de las citas como criterio de autoridad, como medio para no correr riesgos- así como la práctica de la reproducción en los exámenes, representan tácticas estudiantiles ideadas para permanecer en y egresar de la facultad. Los estudiantes van aprendiendo qué es lo que cada profesor reivindica y van actuando en función de ello. Así, la "autoridad del autor" suele ser un resguardo en la situación de examen. La cita opera entonces como garantía de la propia palabra.

- Son reconocidos aquellos profesores "generosos", los que literalmente "no se quedan con el libro bajo el brazo", en contraposición de aquellos que, por ejemplo, luego de hacer alarde de poseer una de las pocas ediciones de un ejemplar, se niegan a ofrecerlo. Este es un proceso que guarda relación con la construcción del libro como objeto sagrado. El tipo de relación planteada con el objeto libro se conecta con la autoridad del autor y los modos de posicionarse frente a esta. Los estudiantes de letras suelen establecer distinciones entre aquellos profesores que plantean una relación estática, fija, dogmática con las obras literarias, ubicándose en el lugar de "guardianes de la tradición" y aquellos que habilitan un juego un tanto más libre de las interpretaciones. Puede ocurrir, respecto de esto último, que se le reconozca autoridad a una cierta tradición -por ejemplo literaria- al mismo tiempo que se manifieste desencanto respecto de la institución encargada de transmitir esa tradición. 


\section{A MODO DE CIERRE}

En la introducción de este capítulo remitíamos a los debates que tienen lugar en torno al problema de la autoridad, señalando la coexistencia entre una dificultad para legitimar posiciones asentadas en la superioridad de unos sobre otros y la multiplicación de referencias que se disputan el derecho a ser reconocidas.

$\mathrm{El}$ análisis de los relatos de estudiantes universitarios próximos a terminar sus estudios en diferentes carreras de la UNR da cuenta de estas ambivalencias y tensiones. Así, si por un lado es claramente visible una desacreditación de los profesores y de los mecanismos institucionales de acceso a la docencia, por otro es evidente la demanda de referentes autorizados que apuntalen el proceso de formación y el reconocimiento de algunos de ellos como figuras claves en la construcción de sus identidades profesionales.

Encontramos, en ese sentido, una compleja convergencia entre la admiración y la aceptación de la superioridad de los profesores sobre la base de la transmisión del conocimiento; modos de resistencia a la autoridad a través del rechazo de ciertas manifestaciones de jerarquía y demandas de reconocimiento de esta como forma de legitimar un vínculo asimétrico sobre el principio de la reciprocidad.

El recorrido realizado permite observar una multiplicidad de sentidos que, bajo la forma de discursos, imágenes, promesas, atraviesan las experiencias de estudiantes de diferentes facultades y carreras, revelando el peso de las culturas disciplinares en la consideración de la autoridad por parte de los estudiantes. Esto nos lleva a afirmar que, indefectiblemente, al encarar estudios sobre la universidad debemos tener en cuenta una perspectiva situada, que atienda las peculiaridades de los diferentes espacios institucionales y áreas del conocimiento.

De cualquier manera, cabe destacar que en todos los casos se hizo alusión a una cuestión que trasciende la especificidad de cada carrera. Y es la figura del "profesor universitario". Todos los jóvenes entrevistados identifican como figuras reconocidas a aquellas personas que poseen un saber y a la vez ciertas claves de su transmisión.

Esto pone en evidencia que el vínculo pedagógico siempre implica una relación. Relación esta que parte de la premisa fundamental de reconocerle al profesor una autoridad que lo acredita como tal, pero que también se construye sobre la base de la reciprocidad y de la enunciación dirigida a alguien.

Por último, el recorrido realizado presenta una multiplicidad de visiones, a veces contrapuestas, pero en las que es posible señalar un punto de convergencia: la creencia de los propios estudiantes en que el encuentro con profesores que encarnaron aquellos principios, rasgos o atributos a su juicio legítimos, fue central en el devenir de sus trayectorias. En otras palabras, no hay relato de estas trayectorias -que podemos considerar exitosas- en el que no se haya mencionado alguna figura profesoral que haya operado como sostén a la institución; o en el que al menos no se haya expresado un deseo de haber contado con ellas.

Dicha búsqueda de seguridad en la fuerza de otros amerita continuar interrogando a la autoridad como aspecto crucial de la experiencia estudiantil, 
indagando en diferentes espacios institucionales las particularidades que asume su crítica, los vacíos que deja su ausencia y el tipo de presencia que se reclama.

\section{REFERENCIAS}

Aвramows ki, Ana Laura. Maneras de querer. Los afectos docentes en las relaciones pedagógicas. Buenos Aires: Paidós, 2010.

Agamben, Giorgio. Infancia e historia. Buenos Aires: Adriana Hidalgo, 2007.

Becher, Tony. Tribus y territorios académicos. Barcelona: Gedisa, 2001.

Bertaux, Daniel. Los relatos de vida. Perspectiva etnosociológica. Barcelona: Edicions Bellaterra, 2005.

Bourdieu, Pierre. Intelectuales, politica y poder. Buenos Aires: Eudeba, 2006.

CLARK, Burton. El sistema de educación superior. México: Nueva Imagen/UNAM, 1983.

De Certeau, Michel. La debilidad de creer. Buenos Aires: Katz, 2006.

Dubet, François. El declive de la institución. Profesiones, sujetos e individuos en la modernidad. Barcelona: Gedisa, 2006.

El declive y las mutaciones de la institución. Revista de Antropología Social, Madrid: Universidad Complutense, v. 16, p. 39-66, 2007.

Dussel, Inés. [Prólogo]. Abramowski, Ana Laura. In: Maneras de querer. Los afectos docentes en las relaciones pedagógicas. Buenos Aires: Paidós, 2010.

. Southwell, Myriam. La autoridad docente en cuestión: líneas para el debate. El Monitor de la Educación, Buenos Aires: Ministerio de Cultura y Educación de la Nación, v. 20, 5 época, p. 26-28, mar. 2009.

Ecclestone, Kathryn; Hayes, Dennis (2008). The dangerous rise of therapeutic education. London: Routledge, 2008.

Glaser, Barney; Strauss, Anselm. The discovery of grounded theory. New York: Aldine Publishing Company, 1967.

Kojève, Alexander. La noción de autoridad. Buenos Aires: Nueva Visión, 2004.

Larrosa, Jorge. La experiencia de la lectura. Estudios sobre literatura y formación. México: Fondo de Cultura Económica, 2003.

Link, Daniel. Quése yo. Testimonio, experiencia y subjetividad. Blog Linkillo, mar. 2006. Disponible en: <www.linkillodraftversion.blogspot.com/2006/03/qu-s-yo.html>.Acceso en: 10 mar. 2009.

Ricoeur, Paul. Sí mismo como otro. Madrid: Siglo Veintiuno, 1996.

. Lo justo. Madrid: Trotta, 2008. v. 2.

Sennett, Richard. El respeto. Barcelona: Anagrama, 2003.

. El artesano. Barcelona: Anagrama, 2009.

Zizer, Slavoj. El espinoso sujeto. Buenos Aires: Paidós, 2007. 


\section{SOBRE LA AUTORA}

María Paula Pierella es doctora en ciencias sociales por la Universidad de Buenos Aires (Argentina). Profesora de la Universidad Nacional de Rosario (Argentina).

E-mail: pierella@irice-conicet.gov.ar 